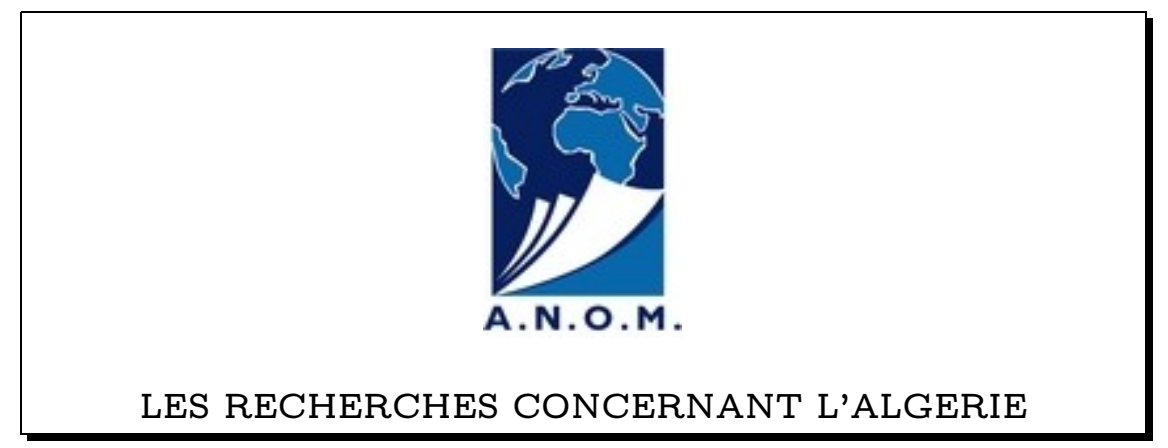

Les Archives nationales d'outre-mer conservent sur l'Algérie :

- des archives ministérielles, provenant de Paris

- des archives locales, provenant du gouvernement général de l'Algérie, de certaines préfectures et communes mixtes

- des fonds d'origine privée sont également consultables.

Avant d'entamer une recherche plus approfondie, vous pouvez consulter l'ouvrage suivant :

"Guide des sources de l'histoire de l'Afrique du Nord et du Proche-Orient dans les archives françaises »(3 volumes)

ou

Site internet des ANOM : voir IREL (Instruments de recherche en ligne) pour l'état des fonds et les inventaires en ligne

http://anom.archivesnationales.culture.gouv.fr/

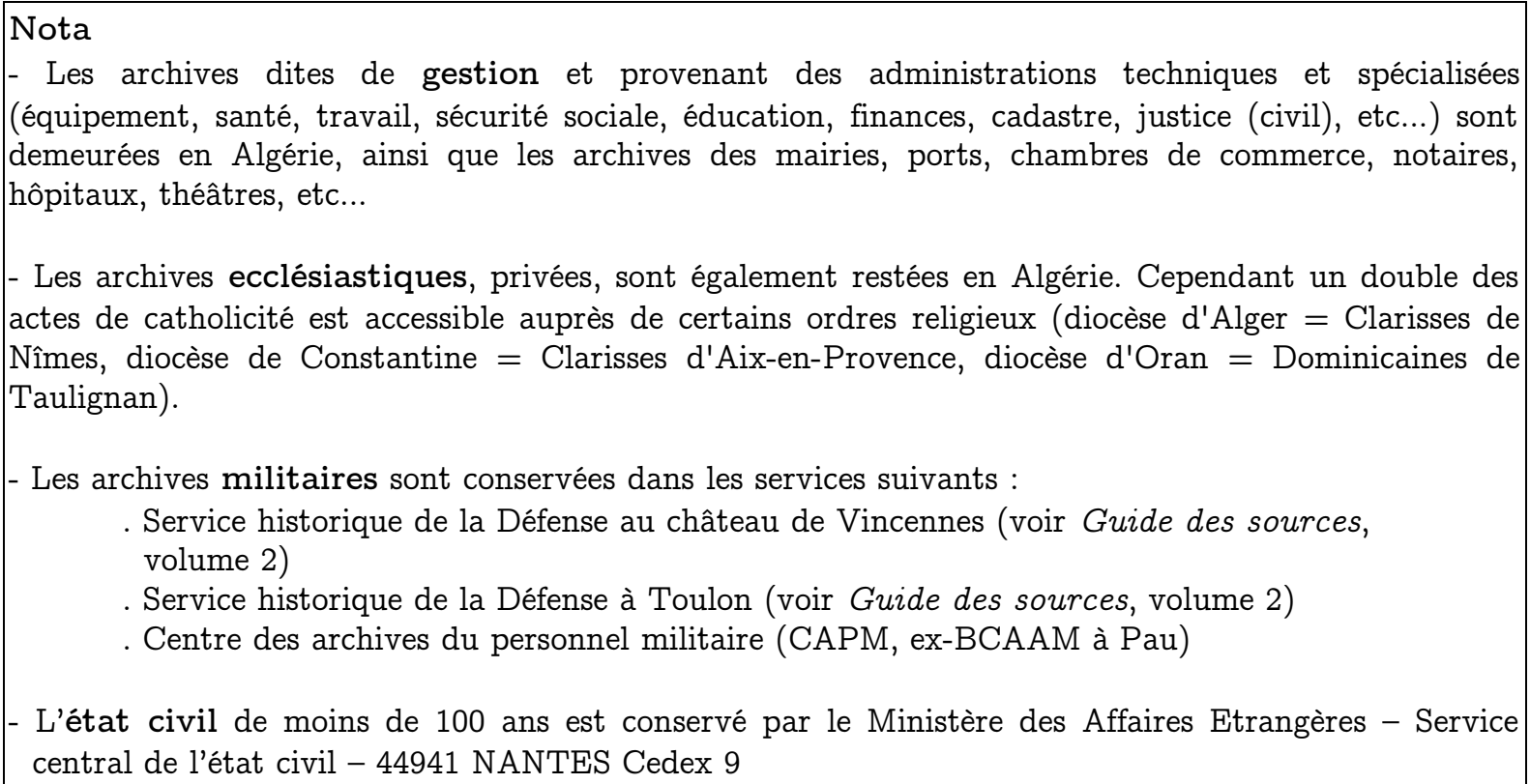

\title{
Archives ministéRIELles
}

Ces documents proviennent :

$1^{\circ}$ ) de la direction des affaires de l'Algérie (rattachée successivement aux ministères de la Guerre, de l'Algérie et des Colonies, de l'Intérieur). Il s'agit de la série F80, très riche, dont la consultation est nécessaire pour l'étude de l'Algérie au XIXe siècle. Il peut être utile de consulter le fonds du ministère des colonies, puis de la France d'Outre-mer : affaires politiques, économiques, commission Guernut, relations avec l'Afrique noire, etc... 
Nota

Les documents relatifs à l'Algérie, provenant des autres ministères et services (agriculture, cultes, etc...) sont conservés aux Archives nationales, site de Paris ou de Fontainebleau.

Voir Guide des sources, volume 1.

$\left.2^{\circ}\right) \mathrm{du}$ Ministère des Affaires algériennes (répertoire en ligne, série 81F)

\section{Archives locales}

\section{Avant 1830}

- Consulats de France à Alger, Bône, Oran, série A (1686-1835)

(Une partie du fonds se trouve au Centre des archives diplomatiques, à Nantes).

- Agences des compagnies commerciales marseillaises en Afrique, série B

- Copies d'archives espagnoles et vaticanes (XIIe, XVIIIe siècles), série C

- Les archives ottomanes, conservées en Algérie, sont consultables sous forme

de microfilms, séries 1 et 15 MIOM

Après 1830

\section{Gouvernement général de l'Algérie}

- Correspondance politique des gouverneurs ; fonds Bugeaud et Gueydon (séries E et EE microfilms)

- Législation, conseils, Assemblée algérienne, série F

- Personnel, administration générale, Service des questions juives, Service des liaisons nordafricaines, sûreté nationale, service pénitentiaire, série G

- Affaires musulmanes et Territoires du Sud, série H (Série très importante par sa richesse et sa variété)

- Bureaux arabes : région d'Alger, séries I et II région d'Oran, séries $\mathrm{J}$ et $\mathrm{JJ}$

région de Constantine, séries $\mathrm{K}$ et $\mathrm{KK}$

(En raison des multiples activités des officiers responsables des bureaux arabes, ces séries offrent un grand intérêt pour les études sur le XIXe siècle).

- Colonisation foncière, création de villages, série L

- Dossiers de demandeurs de lots de colonisation, sous-série 51L (index sur fiches)

- Propriété indigène, exécution du senatus consulte du 22 avril 1863, série M (nombreux renseignements sur les tribus): enquêtes générales, enquêtes partielles (listes nominatives); séquestre

- Travaux Publics (alignements, bâtiments, électricité, mines, hydrocarbures, routes, forts, aviation, chemin de fer), série $\mathrm{N}$

- Services économiques, série O

- Forêts, série P

- Contributions de guerre et indemnités, sous-série $3 \mathrm{Q}$

- Instruction publique et Beaux Arts, série S

- Dossiers de médecins de colonisation, sous-série $1 \mathrm{U}$

- Justice, série T (insurrection de 1871, administration judiciaire)

- Plan d'action communal de 1946 (série Y)

- Acquisitions diverses : collection de papiers privés et de documents

d'origine diverses constituée avant 1962, série X

- Cabinet civil du gouverneur général, série $C A B$

- Cabinet militaire du gouverneur général, série $C M$, série $R$ 
Départements des régions d'Alger, d'Oran, de Constantine

Département des Oasis

- Personnel départemental, série C (index sur fiches)

- Elections politiques, série E

- Police, administration générale, série $F$

- Population, recensements, statistiques, série G

- Agriculture, série H

- Administration des Musulmans, série I (notamment Service des liaisons nord-africaines)

- Cabinets préfectoraux, série $\mathrm{K}$

- Conseils de préfecture (sous-série $7 \mathrm{~K}$ )

- Colonisation foncière : dossiers de demandeurs de lots de colonisation, titres de propriété, création de villages, série $M$

- Propriété indigène, série $\mathrm{N}$

- Eaux et forêts, série $O$

- Domaine public, série $P$

- Milices, affaires militaires, conseils de guerre, bureaux spécialisés de la Défense nationale, série Q

- Instruction publique, Beaux Arts, documentation des archives, série $\mathrm{S}$

- Cultes, série U

- Service des questions juives (régime de Vichy)

- Services de police

- Direction de la Sûreté nationale en Algérie

- Renseignements généraux d'Alger, Oran, Constantine

- Commissariat central d'Alger ; commissariat de police de Tebessa

- D.S.T. d'Algérie

- S.R.P.J. d'Alger, d'Oran, de Constantine

Nota

Les fonds des départements d'Oran et Constantine et des Oasis comportent d'importantes " séries continues ", où les cartons sont rangés par ordre numérique et non répartis par séries thématiques ${ }^{*}$

Sous-préfectures

Aflou, Constantine, Tiaret, Batna, Tebessa.

\section{Communes mixtes}

Actuellement sont consultables les fonds des communes mixtes d'Aïn Temouchent, d'Aïn Touta, d'Aïn M'lila, de Remchi, Sedrata, La Calle, La Séfia, Marnia, Azeffoun.

\section{Sections administratives spécialisées (S.A.S.)}

Les archives de cette structure administrative mise en place à partir de 1955, concernent les régions d'Alger et de Constantine (région d'Oran manquante), série S.A.S.

\section{Registres matricules militaires}

- Ces registres proviennent des bureaux de recrutement d'Alger, Oran et Constantine, à partir de 1864 et jusqu'en 1940 à ce jour (versements ultérieurs prévus), série RM

- Tables alphabétiques, série TAB

* Se renseigner auprès du président de salle 
Nota : Les registres sont restés en Algérie. Une grande partie de ces registres a été microfilmée par le ministère des Affaires étrangères entre 1967 et 1972. Les microfilms sont conservés à Nantes au Service Central de l'Etat Civil. C'est à partir de ceux-ci qu'a été effectuée la numérisation des actes mis en ligne sur le site des ANOM..

Consulter :

- la série de microfilms 77 MIOM (tables décennales)

- les actes numérisés, sur le site internet des ANOM :

http://anom.archivesnationales.culture.gouv.fr/caomec2/recherche.php?territoire=ALGERIE

\section{Banque d'Algérie et de Tunisie}

Archives du siège social et des agences

Pour les archives des entreprises, contacter les Archives nationales du monde du travail, A.N.M.T. à Roubaix (59)

http://www.archivesnationales.culture.gouv.fr/camt/index.html

\section{Archives privées}

Rappel : série X du gouvernement général de l'Algérie

Consulter aussi les séries APOM, APC, EVEOM, Comité français pour l'Outre-mer, ainsi que la série $\mathrm{AQ}$, consacrée aux archives d'entreprises (chemin de fer transsaharien, papiers A. Berthelot, 10AQ ; chemin de fer Bône-Guelma, 156 AQ).

Les archives privées connaissent un accroissement régulier, grâce aux dons des particuliers (contacter les Archives nationales d'outre-mer, si vous désirez donner des documents).

\section{Iconographie}

Cartes postales, photographies, gravures, cartes, affiches sur l'Algérie avant et après 1830 : consultables sur la base d'images Ulysse sur le site des ANOM. L'iconographie est mise en ligne au fur et à mesure des campagnes de numérisation :

http://anom.archivesnationales.culture.gouv.fr/sdx/ulysse/index

\section{LES RECHERCHES CONCERNANT LE MAROC ET LA TUNISIE}

Les archives des protectorats français sur la Tunisie et le Maroc sont conservées au Centre des archives diplomatiques à Nantes :

http://www.diplomatie.gouv.fr/fr/le-ministere/archives-et-patrimoine/colonne-droite-5491/salles-delecture/article/nantes

Celles des services ministériels responsables sont conservées par le service des archives du ministère des Affaires étrangères, à La Courneuve. Voir Guide des sources, volume 2.

http://www.diplomatie.gouv.fr/fr/le-ministere/archives-et-patrimoine/colonne-droite-5491/salles-delecture/article/la-courneuve

Seuls certains documents conservés aux Archives nationales d'outre-mer se rapportent à ces pays (questions de frontières, contrebande, affaires politiques) : consulter les sous-séries $22 \mathrm{H}, 25-$ 27H, 30-32H, les séries I, II, K, KK, ainsi que le fonds du ministère de la France d'Outre-mer,Direction des Affaires politiques, SLOTFOM (Service de Liaison avec les Originaires des Territoires Français d'Outre-mer), commission Guernut, etc...

Inventaires FM 21-28 